\title{
IDENTIFYING THE ISSUE OF REDUCING THE EMISSION OF HARMFUL COMPOUNDS IN THE EXHAUST GAS FROM MARINE MAIN ENGINES AND DESCRIPTION OF THE EMISSION PROCESS OF THESE COMPOUNDS IN PROBABILISTIC APPROACH
}

ZbigniewŁosiewicz

West Pomeranian University of Technology Szczecin, Poland

\begin{abstract}
The article discusses the results of actions performed by marine engine manufacturers towards the reduction of emission of harmful substances in the exhaust gas from these engines. The discussion is limited to main engines produced by MAN B\&W. A model is proposed to describe the process of emission of harmful substances from Diesel engines based on the semi-Markov process, discrete in states and continuous in the operating time. The states of this process are: engine ability state $\left(s_{1}\right)$ and engine inability state $\left(s_{2}\right)$. A method to calculate probabilities $P_{1}$ and $P_{2}$ of the appearance of states $s_{1}$ and $s_{2}$ is proposed. State $s_{1}$ is interpreted as corresponding to the inequality $e_{k}<e_{k(d o p)}$, while state $s_{2}$ is characterised by the inequality $e_{k}>e_{k(d o p)}$, where $e_{k}$ represents the mass of harmful substances emitted by the engine during its operation and $e_{k(d o p)}$ is the maximum mass of emission of these substances permitted by relevant regulations.
\end{abstract}

Keywords: ship's main engine; semi-Markov process; Diesel engine; harmful substance

\section{INTRODUCTION}

The International Maritime Organisation (IMO) has introduced legal acts with more severe requirements concerning marine environment protection. These requirements enforced scientific institutions $[2,5,21,7,9$, 20] and marine Diesel engine manufacturers to perform research activities oriented on reducing the emission of such harmful substances (toxic compounds) as: carbon oxide $(\mathrm{CO})$, hydrocarbons $\left(\mathrm{C}_{\mathrm{n}} \mathrm{H}_{\mathrm{m}}\right)$, nitrogen oxides (NO and $\left.\mathrm{NO}_{2}\right)$, sulphur compounds $\left(\mathrm{SO}_{2}, \mathrm{SO}_{3}, \mathrm{H}_{2} \mathrm{SO}_{3}, \mathrm{H}_{2} \mathrm{SO}_{4}\right)$, aldehydes, solid particles, and other substances [3, 18]. Particular attention was focused on marine main engines, i.e. engines used for ship propulsion. Among other issues, the performed research activities included developing methods to reduce the emission of harmful compounds and analysing the result of their application, which is of high importance in optimising the operation of these engines with respect to pro-ecological criteria. In the engine operation process, the amounts of the emitted toxic compounds vary randomly. That is why the article proposes to analyse the real process of their emission as the stochastic process $\{V(t): t \geq 0\}$ with values having the form of engine states determined from mass measurements of harmful substances emitted by the Diesel engine to the environment. The proposed model of this process has the form of a semi-Markov process $\{U(t): t \geq 0\}[5,1]$, continuous in time, the values of which are properly defined states of engine ability $\left(s_{1}\right)$ and inability $\left(s_{2}\right)$.

\section{THE PROBLEM OF REDUCING THE MASS OF HARMFUL COMPONUDS EMITTED IN THE SHIP'S MAIN ENGINE EXHAUST GAS AND THE NEED TO ASSESS THIS MASS}

On 19 May, 2005, the International Maritime Organisation introduced Annex VI to the MARPOL 73/78 Convention on preventing atmosphere pollution by ships. This annex has forced the ship owners to use certain solutions to reduce the emission of harmful substances to the atmosphere. 
As a result, now the manufacturers of marine Diesel engines, especially main engines, make attempts not only to achieve the best possible energy efficiency indicators and high reliability and durability of the manufactures engines, along with low environment pollution [19, 24, 1, 9], but also to reduce the emissions of toxic compounds, the largest amounts of which are generated when starting the engine $[2,13,14,23$, 7]. During this starting time, peroxides and hydroxides are generated as a result of chain reactions, and then are subject to disintegration. Products of this disintegration react with oxygen to create aldehydes, acids, steam, and carbon oxide and dioxide [9]. Due to (global or local) deficiency of oxygen, large volumes of carbon oxide, a toxic exhaust gas component, are generated during the combustion.

It results from fuel combustion process examination that the amount of a certain toxic compound emitted in the exhaust gas is highly affected by physical, and not chemical processes. Moreover, the emissions of particular compounds are closely related with each other and reducing the emission of one compound may lead to the increased emission of another toxic compound.

Taking into account IMO requirements and USA (EPA) regulations concerning the impurity emission level in the exhaust gas, along with the abovementioned aspects of generation of toxic exhaust gas components, the company MAN \& BW initiated examination of the continuous combustion process which has led to the development of a concept to build an ecological engine.

Based on the results of this examination, MAN B\&W defined and adopted "typical" proportions of the components delivered to the combustion chamber and emitted in the exhaust gas, Fig. 1.

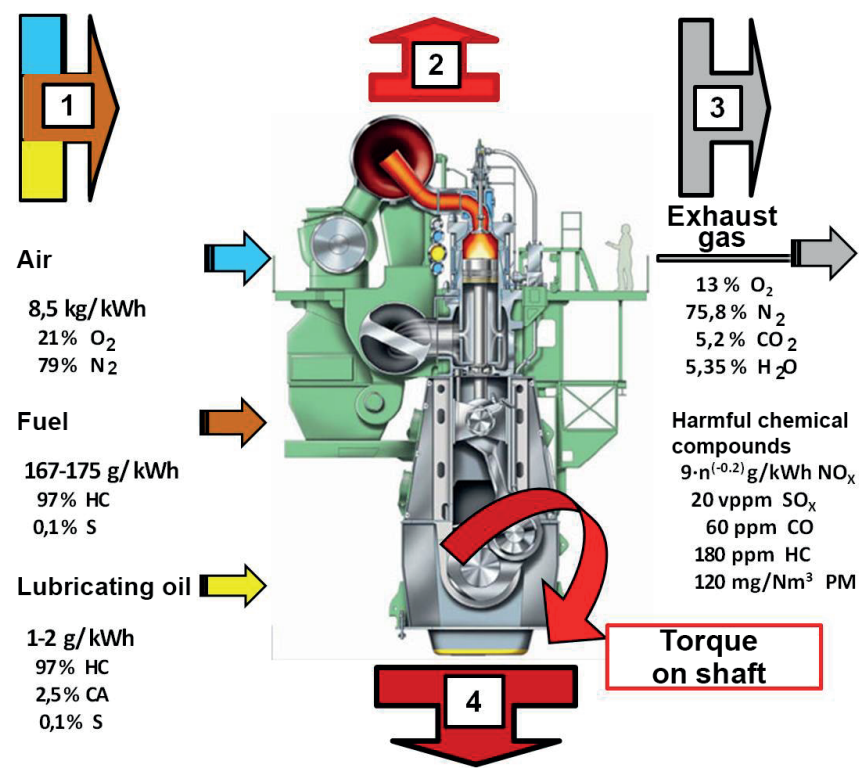

Fig. 1. Proportions of energy carrying substances delivered to the engine and the contents of the engine exhaust gas [2]
The solutions developed by MAN\& BW to reduce the emission of harmful chemical compounds can be divided into primary and secondary ones. One of primary solutions refers to techniques which delay the fuel injection time in $\mathrm{MC}-\mathrm{C}$ and $M E-C$ type engines. Minor injection time changes provide opportunities for a relatively wide control of the injection time and fuel delivery (Fig. 2).

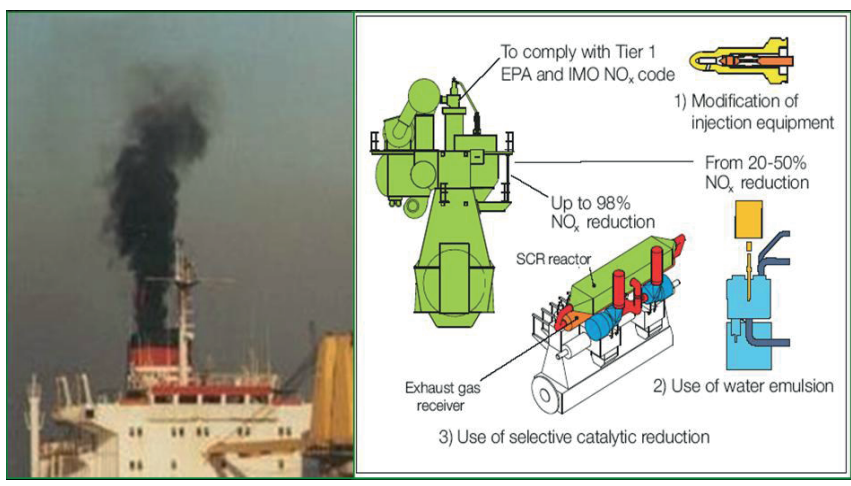

Fig. 2. Solution which enables to reduce the level of emission of harmful compounds in the exhaust gas to the level required by EPA and IMO [3]

This solution allows to control the combustion process within the entire engine load range and to reduce the level of $\mathrm{NO}_{\mathrm{x}}$ emission (Fig. 3).

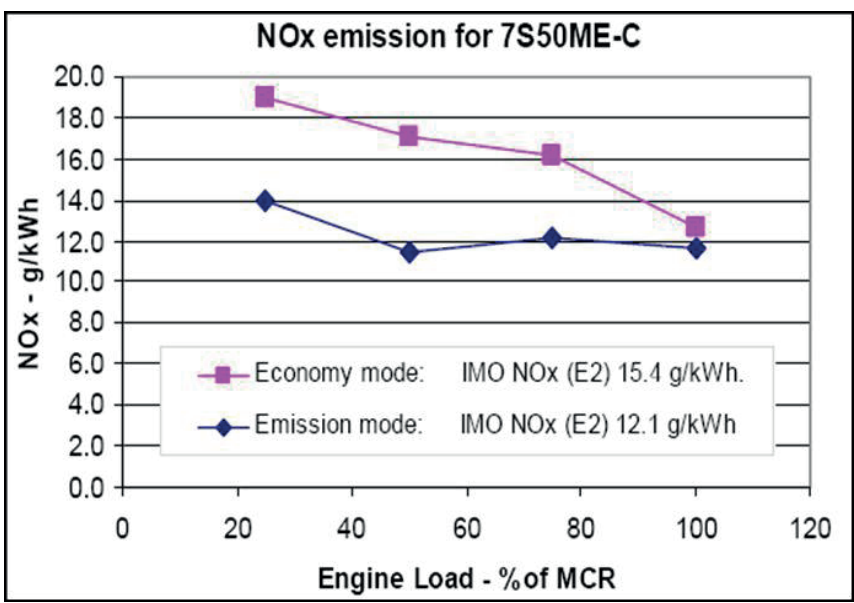

Fig. 3. Diagrams of $\mathrm{NO}_{x}$ emissions in different engine operation modes [12]

Moreover, certain changes were introduced to the design of the injection valves, which were changed to slide valve type (Fig. 4). After closing, these valves do not „store” redundant fuel (sac volume $=0 \mathrm{~mm}^{3}$ ), which in older type valves leaked away, thus increasing the amount of the created particulates and the resultant coking of valve tips (Fig. 4a). The amounts of particulates generated when using older type valves and the new generation slide valve are shown in the diagram in Fig. $4 \mathrm{~b}$. 


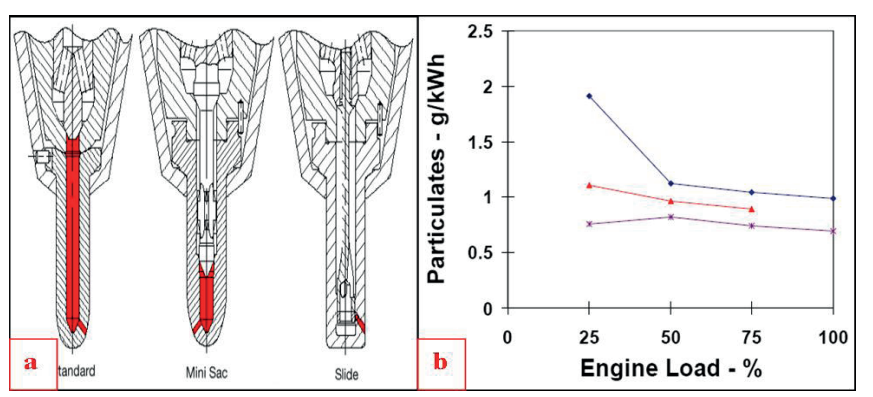

Fig. 4. a) Comparing the designs of conventional fuel injection valves and the new generation slide valve, b) Amounts of particulates generated when using conventional valves and the new generation slide valve [12]

A new method and system of cylinder liner lubrication were applied to reduce the emission of particulates by adapting the amounts of the lubricating oil to both the engine load and the sulphur content in the fuel. Such a lubricating system is schematically shown in Fig. 5.

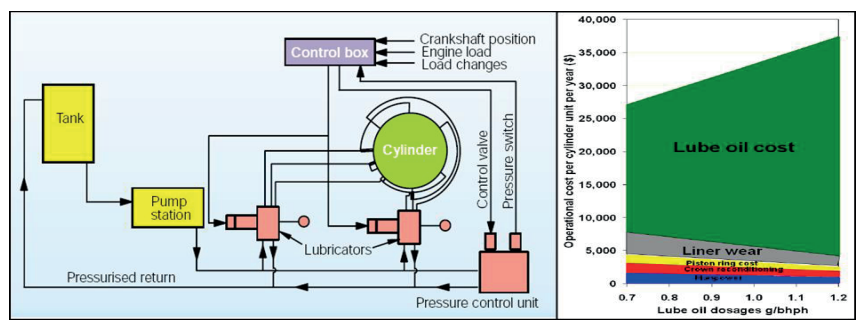

Fig. 5. a) Scheme of the cylinder liner lubrication system, b) Specific cylinder oil consumption cost [18]

Particulates affect negatively human health and, simultaneously, increase the wear of piston rings, cylinder liners, and piston ring grooves, being also the cause of seizure of piston rings in these groves. That is why tests were performed to examine the amounts of generated particulates as a function of the amount of the used cylinder lubrication oil. The results of this examination are shown in Fig. 6.

Beside the above primary methods, so-called secondary methods have also been developed to reduce the emission of harmful chemical compounds. In one of those methods, use is made of fuel-water emulsion which enables to reduce the amount of $\mathrm{NO}_{\mathrm{x}}$ by $20 \div 50 \%$, depending on water amount $[4,17]$.

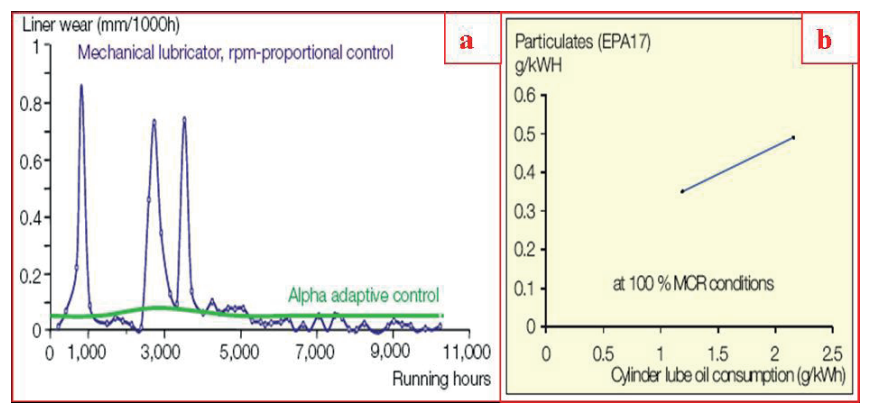

Fig. 6. a) Wear of cylinder liner sliding surface vs. lubricating system type, b) Amount of particulates vs. amount of consumed cylinder lubrication oil [18].
Figure 7 shows the amount of the generated $\mathrm{NO}_{x}$ as a function of the amount of water in the fuel-water emulsion. Higher amounts of water increase the viscosity of the emulsion, as a results of which the emulsion needs to be heated to higher temperature, $170^{\circ} \mathrm{C}$ at $50 \%$ water percentage, and the pressure in the emulsion installation is to be increased. To avoid vanadium corrosion, distilled water is used in the process. The applied $\mathrm{NO}_{\mathrm{x}}$ reduction method bases on decreasing the maximum combustion temperature by supplying the combustion chamber with gases (steam and exhaust gas) having higher specific heat than air. The results of MAN B\&W's efforts to reduce the emission of harmful compounds in the exhaust gas are shown in Fig. 7.

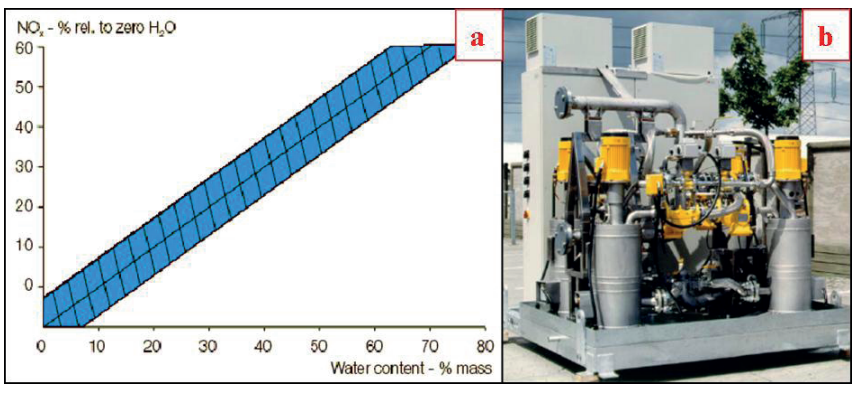

Fig. 7. a) NO amount as function of water content in the fuel-water emulsion, b) fuel-water emulsion homogeniser for $40 \mathrm{MW}$ two-stroke low-speed engine

$$
[3,12]
$$
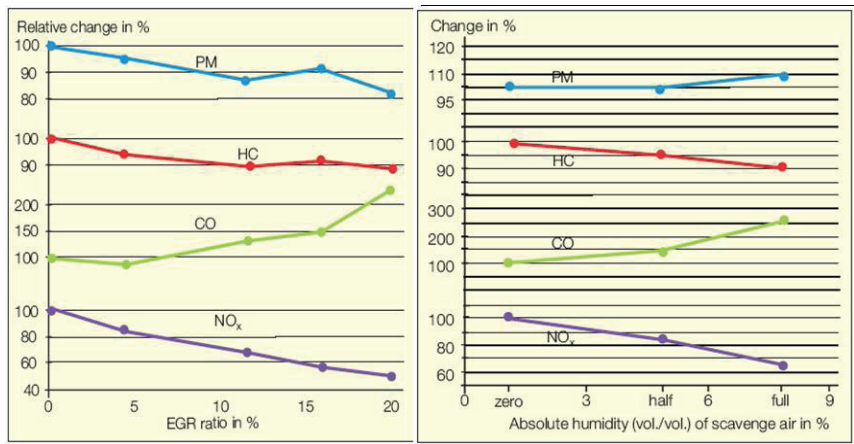

Fig. 8. The effect of EGR ratio (left) and air humidity (right) on the amount of emitted impurities [3]

Indeed, the presented results of MAN B\&W's efforts to reduce the emission of harmful compounds in the exhaust gas and keep it at the possible lowest level look very interesting. However, ship main engines are subject to wear during ship operation, which significantly increases the emission of harmful substances. In this situation, periodical (of even continuous) measurements are needed to estimate the current emission and formulate prognoses on its future trend. This information would make it possible to predict the appearance of the engine inability state $\left(s_{2}\right)$, when the mass $\left(e_{k}\right)$ of the emitted harmful substances is higher than the permissible $\operatorname{limit}\left(e_{k(\mathrm{dop})}\right)$.

The mass of harmful substances emitted in the exhaust gas can be calculated from the formula $[2,7]$ : 


$$
e_{k}=\frac{v_{m i x} \rho_{k} K_{H} c_{k}}{s} 10^{-6}
$$

where $k=1,2, \ldots, n$ is the type (ordinal number) of the given harmful substance, and:

$e_{k} \quad-$ mass of harmful substance $[\mathrm{g} / \mathrm{km}]$,

$v_{\text {mix }} \quad$ - volume of diluted exhaust gas in normal conditions $\left[\mathrm{dm}^{3} /\right.$ test $]$,

$\rho_{k} \quad-$ density of harmful substance in normal conditions $\left[\mathrm{g} / \mathrm{dm}^{3}\right]$,

$K_{M} \quad$ - correction coefficient for humidity of the mass of nitrogen oxides,

$c_{k}-$ concentration of harmful substance [ppm],

$s \quad$-distance covered by ship during the test $[\mathrm{km}]$.

The measurement based confirmation that the emission $e_{k}$ of harmful compounds (1) in the exhaust gas is lower than the permissible limit $e_{k(\mathrm{dop})}$, i.e. $e_{k}<e_{k(\mathrm{dop})}$, means that the engine is in the ability state $\left(s_{1}\right)$ and can perform its task, as its proecological properties are still preserved. On the other hand, when the emission of harmful compounds in the exhaust gas is higher than the limit, i.e. $e_{k}>e_{k \text { (dop) }}$, that means that the engine is in the inability state $\left(s_{2}\right)$ and cannot perform its tasks any longer. An important attribute of states $s_{1}$ and $s_{2}$ is that they appear randomly in each engine during its operation. Consequently, the abovementioned states $s_{1}$ and $s_{2}$ occurring during the main engine operation, like for any other internal combustion engine installed on the ship, can be considered as values of the process $\{V(t): t \geq 0\}$ with random values. Estimating the appearance probabilities for states $s_{1}$ and $s_{2}$ requires a mathematical model in the form of a stochastic process $\{U(t): t \geq 0\}$, adequate to the real process $\{V(t): t \geq 0\}$ and describing the appearance of states $s_{1}$ and $s_{2}$. It results from the properties of this process that the appearance of state $s_{2}$ depends solely on the previous state $s_{1}$ and not on earlier states. This results from the fact that it is state $s_{1}$ which is going to be kept during well-balanced ship engine operation. State passing from $s_{1}$ to $s_{2}$ always provokes an engine user's action to restore good operating properties of the engine, i.e. to return to state $s_{1}$. Therefore we can say that the appearance of state $s_{2}$ and the time of its duration depend only on state $s_{1}$ which had place directly before state $s_{2}$. Consequently, the model of the real process $\{V(t): t \geq 0\}$ of the appearance of states $s_{1}$ and $s_{2}$ can have the form of a mathematical model of semi-Markov processes. The theory of semi-Markov processes says that for the process $\{V(t): t \geq 0\}[10,16,7,9]$ :

1) the Markov condition is fulfilled which expects the future evolution of states of an arbitrary engine (the process of changes of its technical states) for which the semi-Markov model is built to depend solely on its state at a given time and not on its functioning in the past. In other words: the engine's future depends only on its present and not of its past;

2) random variables $T_{i}$ (each representing the duration time of state $s_{i}$, regardless of the state taking place after it) and $T_{i j}$ (representing the duration time of state $s_{i}$ provided that the next state of this process is state $s_{j}$ ) have other distributions than exponential distribution.

Therefore we can say that the model of the real process $\{V(t): t \geq 0\}$ should have the form of a semi-Markov process $\{U(t): t \geq 0\}$, continuous in time and with two states: $s_{1}$ and $s_{2}$.

\section{MODEL OF THE PROCES OF EMISSSION OF HARMFUL COMPOUNDS IN THE EXHAUST GAS}

The process $\{U(t): t \geq 0\}$ as the model of the real process $\{\mathrm{V}(\mathrm{t}): \mathrm{t} \geq 0\}$ is the semi-Markov process, with two states and continuous realisation (time-continuous process). This process has the values belonging to the set of states:

$$
S=\left\{s_{1}, s_{2}\right\}
$$

having the following interpretation:

- the engine ability state $s_{1}$ exists when the inequality $e_{k}<e_{k \text { (dop) }}$ holds for $\mathrm{k}=1,2, \mathrm{n}$

- the engine inability state $s_{2}$ exists when the inequality $e_{k}>e_{k(\text { dop })}$ holds.

$\mathrm{k}=1,2, \mathrm{n}$,

The graph of changes of states $s_{i}(i=1,2, \mathrm{i} \neq \mathrm{j})$ of the process $\{U(t): t \geq 0\}$ and, consequently, the engine state changes, has the form shown in Fig. 9.

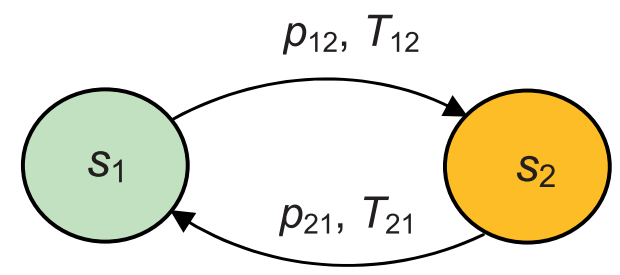

Fig. 9. Graph of changes of technical states of the engine: $p_{i j}$-probability that the engine passes from state $s_{i}$ to state $s_{j}, T_{i j}$-duration time of state $s_{i}$ provided that the next state of the process is state $s_{j} ; i \neq j ; i, j=1,2$

Since the process $\{U(t): t \geq 0\}$ is the semi-Markov process, changes of its states $s_{i}(\mathrm{i}=1,2)$ take place at times $\tau_{0}, \tau_{1}$, $\tau_{2}$, which are random variables with different probability distributions fulfilling the condition:

$$
\begin{aligned}
P\left\{Y\left(\tau_{n+1}\right)\right. & \left.=s_{j}, \tau_{n+1}-\tau_{n}<\tau \mid Y\left(\tau_{n}\right)=s_{i}, Y\left(\tau_{n-1}\right), \ldots Y\left(\tau_{1}\right), Y\left(\tau_{0}\right), \tau_{n}-\tau_{n-1}, \ldots, \tau_{1}-\tau_{0}, \tau_{0}\right\}= \\
& =P\left\{Y\left(\tau_{n+1}\right)=s_{j}, \tau_{n+1}-\tau_{n}<\tau \mid Y\left(\tau_{n}\right)=s_{i}\right\}
\end{aligned}
$$

The initial distribution of this process is given by the formula (3)

$$
P_{i}=P\left\{U(0)=s_{i}\right\}=\left\{\begin{array}{lll}
1 & \text { for } & i=1 \\
0 & \text { for } & i=2
\end{array}\right.
$$


while its functional matrix has the form:

$$
\mathbf{Q}(\mathbf{t})=\left[\begin{array}{cc}
0 & Q_{12}(t) \\
Q_{21}(t) & 0
\end{array}\right]
$$

For the process $\{U(t): t \geq 0\}$ we can calculate its limiting distribution from the formula $[5,22,18,17]$ :

$$
P_{j}=\frac{\pi_{j} \cdot E\left(T_{j}\right)}{\sum_{k=1}^{3} \pi_{k} \cdot E\left(T_{k}\right)}, j=1,2,3
$$

The distribution $\pi_{j}(j=1,2,3)$ in formula (5) is the limiting distribution for the Markov chain $\left\{Y\left(\tau_{n}\right): n=0,1,2,3, \ldots\right\}$ imbedded into the process $\{U(t): t \geq 0\}$. As results from the functional matrix (4), this distribution satisfies the equation system [18]:

$$
\begin{aligned}
& {\left[\pi_{1}, \pi_{2}\right] \cdot\left[\begin{array}{cc}
0 & p_{12} \\
p_{21} & 0
\end{array}\right]=\left[\pi_{1}, \pi_{2}\right]} \\
& \pi_{1}+\pi_{2}+\pi_{3}=1
\end{aligned}
$$

The solution to the equation system (6), taking into account formula (5), are the probabilities:

$$
P_{1}=\frac{E\left(T_{1}\right)}{M}, P_{2}=\frac{p_{2} \cdot E\left(T_{2}\right)}{M}
$$

where

and:

$$
M=E\left(T_{1}\right)+p_{2} \cdot E\left(T_{2}\right)
$$

$P_{1}, P_{2}$ - probabilities that the Diesel engine is in state $s_{1}$ or $s_{2}$, respectively

$\pi_{\text {- }}$-limiting probability of the Markov chain imbedded into the process $\{U(t): t \geq 0\}$, which describes the probability of appearance of state $s_{j}, j=1,2$,

$p_{i j}$ - probability of passing of the process $\{U(t): t \geq 0\}$ from state $s_{i}$ to state $s_{j}$; $1,2)$.

$E\left(T_{j}\right)$-expected value of the duration time of state $s_{j}(j=$

The set of Diesel engine states $S=\left\{s_{1}, s_{2}\right\}$ can be considered as the set of values of the stochastic process $\{U(t): t \geq 0\}$ with piecewise constant and right-continuous realisations. A sample realisation of this process is shown in Fig. 10.

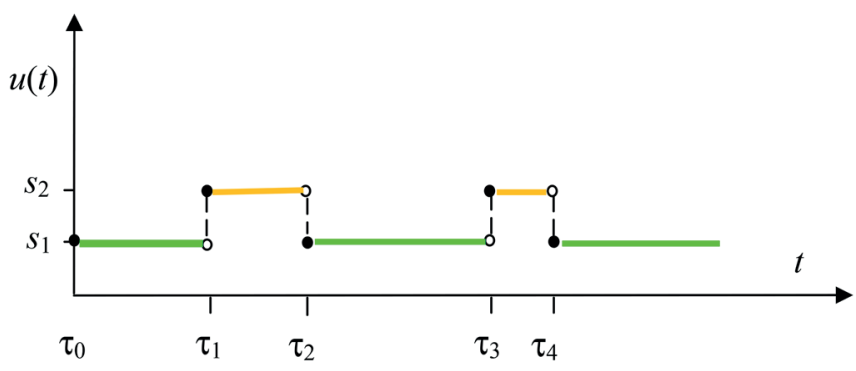

Fig. 10. Sample realisation of the engine operation process $\{U(t): t \geq 0\}$ : $\{u(t): t \in T\}$ - realisation of the process of technical state changes, $t$ - time of operation; $s_{1}$-ability state, $s_{2}$-inability state
For different reasons [2, 15, 21, 22], the emission of sulphur compounds $\left(\mathrm{S}_{\mathrm{n}} \mathrm{O}_{\mathrm{x}}\right)$, hydrocarbons $\left(\mathrm{C}_{\mathrm{n}} \mathrm{H}_{\mathrm{m}}\right)$, carbon oxide $(\mathrm{CO})$, and nitrogen oxides $\left(\mathrm{NO}_{\mathrm{x}}\right)$ in the exhaust gas is much higher when the engine is in state $s_{2}$ than in state $s_{1}$.

Calculating approximate values of probabilities $P_{j}(j=1,2)$, requires assessing the values of probabilities $p_{i j}$ and the expected values $\mathrm{E}(T)$, where $i=1,2$ and $j=1,2$, whereby $\mathrm{i} \neq \mathrm{j}$.

Assessing $p_{i j}$ and $\mathrm{E}\left(T_{j}\right)$ is possible if we know the realisation $\mathrm{u}(\mathrm{t})$ of the process $\{U(t): t \geq 0\}$ within a relatively long time interval, i.e. for $t \in\left[0, t_{b}\right]$, where $t_{b}>>0$. Then we can assess numbers $n_{i j}(i, j=0,1, \ldots 3 ; i \neq j)$, which represent the number of passes from state $s_{i}$ to $s_{i}$ in a relatively long time.

The estimator of the most likely probability of the pass $p_{i j}$ is the statistics [10].

$$
\hat{P}_{i j}=\frac{N_{i j}}{\sum_{j=1}^{2} N_{i j}}, \quad \mathrm{i} \neq \mathrm{j} ; \mathrm{i}, \mathrm{j}=1,
$$

the value $\hat{p}_{i j}=\frac{n_{i j}}{\sum_{j=1}^{2} n_{i j}} \mathrm{c}$ of which is the assessment of the unknown probability $p_{i j}$ that the process $\{\mathrm{U}(\mathrm{t}): \mathrm{t} \geq 0\}$ passes from state $s_{i}$ to state $s_{j}$.

The abovementioned realisation $u(\mathrm{t})$ of the process of technical state changes can also be used to obtain realisations $t_{j}^{(m)}, m=1,2, . ., n_{i j}$ of random variables $T_{j}$. Point estimation facilitates assessing $\mathrm{E}\left(T_{j}\right)$ as the arithmetic mean of realisations $t_{j}^{(m)}[10,11]$.

\section{CONCLUSIONS}

The article presents efforts of marine engine manufacturers to reduce the emission of harmful substances in the exhaust gas from main engines, based on MAN B\&W achievements as an example.

It has been shown that the emission of harmful substances in the exhaust gas from these engines, analysed during their lifetime, can be considered the result of engine's technical state changes described by the stochastic process $\{U(t): t \geq 0\}$ with states of engine ability $\left(s_{1}\right)$ and inability $\left(s_{2}\right)$. It was also shown that the Markov condition can be considered fulfilled which says that the future evolution of the above states for an arbitrary engine (process of changes of its technical states) for which the semi-Markov model $\{U(t): t \geq 0\}$ is created depends only on its state at a given time and not on its past functioning, i.e. the engine future depends only on its present and not on its past.

A two-state semi-Markov model was proposed for the process of emission of harmful substances in the exhaust gas from ship internal combustion engines. The intensity of this emission depends on technical state of the engine. Two types of engine's technical states were taken into account, which were the state of engine ability $\left(s_{1}\right)$ and inability $\left(s_{2}\right)$. The ability state is characterised by lower emission $e_{k}$ of harmful 
compounds in the exhaust gas than the permissible limit $e_{k \text { (dop) }}$, which means the fulfilment of the inequality $e_{k}<e_{k \text { (dop) }}$, while the inability state is characterised by the emission $e_{k}$ of harmful compounds in the exhaust gas which exceeds the permissible limit $e_{k \text { (dop) }}$, with the resultant fulfilment of the inequality $e_{k}>e_{k(\mathrm{dop})}$.

\section{BIBLIOGRAPHY}

1. Analysing possibilities of application of pro-ecological fuels in internal combustion engines of inland passenger ships in the aspect of their durability, reliability and cost efficiency of their operation, taking into account ship refuelling issues (in Polish). Research work No. 183/E/05 done within the framework of Project EUREKA INCOWATRANS E-3065.

2. Bielaczyc P., Merkisz J., Pielecha J.: Thermal state of internal combustion engine and resultant emission of harmful compounds (in Polish). Wydawnictwo Politechniki Poznańskiej, Poznań 2001.

3. Emission Control, MAN B\&W Two-Stroke Low-Speed Diesel Engines. MAN B\&W Diesel A/S, Copenhagen 2004.

4. Geist M.: Sulzer RTA-T - Technology Review. Wartsila NSD Switzerland Ltd., Winterthur 1998.

5. Girtler J.: Physical aspect of application and usefulness of semi-Markovian processes for modeling the processes occurring in operational phase of technical objects. Polish Maritime Research, No 3(41) 2004, Vol. 11, pp. 25-30.

6. Girtler J., Kuszmider S., Plewiński L.: Selected issues of operation of sea-going vessels in the aspect of navigation safety (in Polish). Monograph. WSM, Szczecin 2003.

7. Girtler J.: A probabilistic method to determine the mass of harmful substances emitted by a Diesel engine during its start (in Polish). ZN Akademii Morskiej w Szczecinie. R10, No. 82 (2006), pp. 193-204.

8. Girtler J.: Identifying operating conditions of crankshaftpiston system of marine main engines. Report on research activities done within the framework of Project N N509 494638 financed by the Ministry of Science and Higher Education. The individual research project entitled: „Decision making based control of theprocess of crankshaft and piston system operation of main propulsion engines on sea-going vessels using technical diagnostics and taking into account safety and environment protection (in Polish).Research works No. 01/10/PB. Gdansk University of Technology, Faculty of Ocean Engineering and Ship Technology, Gdansk 2010.
9. Girtler J., Łosiewicz: Analysing properties of the diagnostic model for crankshaft and piston systems, adapted for the needs of rational control of operation of these engines in the aspects of ship and marine environment safety. Report on research activities done within the framework of ProjectN N509 494638 financed by the Ministry of Science and Higher Education. The individual research project entitled: „Decision making based control of the process of crankshaft and piston system operation of main propulsion engines on sea-going vessels using technical diagnostics and taking into account safety and environment protection (in Polish). Research works No. 06/10/PB. Gdansk University of Technology, Faculty of Ocean Engineering and Ship Technology, Gdansk 2010.

10. Grabski F.: Theory of semi-Markovprocesses of technical object operation (in Polish). Zeszyty Naukowe AMW, No. 75 A, Gdynia 1982.

11. Grabski F.: Semi-Markov models of reliability and operation (in Polish). IBS PAN. Series BADANIA SYSTEMOWE, vol.30, Warsaw 2002.

12. Henningsen S.: Clin Ships: Advanced Technology for Clean Air. MAN Diesel A/S, San Diego, February 2007.

13. Höglund P.G., Ydstedt A.: Reduced Air Pollution and Fuel Consumption with Preheated Car Engines. Urban Transport and the Environment for the 21st Century, International Conference, Lisbon 1998.

14. Larson R.E.: Vehicle Emission Characteristics under Cold Ambient Conditions. SAE Technical Paper 890021.

15. Lindl B., Schmotz H.G.: Cold Start Equipment for Diesel Direct Injection Engines. SAE Technical Paper 1999-01-1244.

16. Lotko W.: Supplying internal combustion engines with alternative fuels (in Polish). ITE, Radom 1995.

17. Łosiewicz Z.: Operating qualities of the diagnosing system CoCoS produced by MAN\&BW for marine Diesel engines (in Polish). Zeszyty Naukowe No. 162 K/2, AMW w Gdyni, pp. 249-260, AMW w Gdyni, Gdynia 2005.

18. ME Engine - the New Generation of Diesel Engines. MAN B\&W Diesel AS, Copenhagen 2003.

19. Piotrowski I., Witkowski K.: Operation of ship internal combustion engines (in Polish). AM, Gdynia 2002.

20. Rudnicki J., Zadrąg R.: Problems of modelling toxic compounds emitted by a marine internal combustion engine in unsteady states. Journal of Polish Maritime Research, No.4(84) 2014, Vol.21 pp.57-65. 2014. 
21. Samhaber Ch., Wimmer A., Loibner E., Bartsch P.: Simulation of Engine Warm-Up. 21 Internationales Wiener Motorensymposium, Vienna 2000.

22. Scuffled A.: Vrbesserung der Kaltstartfähigkeit und Reduzierung der Rauchemissionen bei Kaltstart und Warmlauf von Dieselmotoren durch Ansaugluftvorwärmung mit einen Brennersystem variable Leistung. PIERBUNG AG, Neuss 1997.

23. Swedish Environmental protection Agency and Motortestcenter of the Swedish Motor Vehicle Inspection Company. Cold Climate Emissions 1993.

24. Wajand J.A.: Diesel engines (in Polish). WNT, Warszawa 1988

\section{CONTACT WITH THE AUTHOR}

Zbigniew Łosiewicz

e-mail:zbigniew.losiewicz@zut.edu.pl

Faculty of Maritime Technology and Transport West Pomeranian University of Technology Szczecin Al. Piastów 41

71-065 Szczecin,

Poland 